This item was submitted to Loughborough's Research Repository by the author.

Items in Figshare are protected by copyright, with all rights reserved, unless otherwise indicated.

\title{
Simulation of photosensor-based hairiness measurement using digital image analysis
}

PLEASE CITE THE PUBLISHED VERSION

http://dx.doi.org/10.1080/00405000701462443

PUBLISHER

Taylor and Francis / @ The Textile Institute

VERSION

AM (Accepted Manuscript)

LICENCE

CC BY-NC-ND 4.0

\section{REPOSITORY RECORD}

Ozkaya, Yasar A., Memis Acar, and Michael R. Jackson. 2019. "Simulation of Photosensor-based Hairiness Measurement Using Digital Image Analysis”. figshare. https://hdl.handle.net/2134/13355. 
This item was submitted to Loughborough's Institutional Repository (https://dspace.lboro.ac.uk/) by the author and is made available under the following Creative Commons Licence conditions.

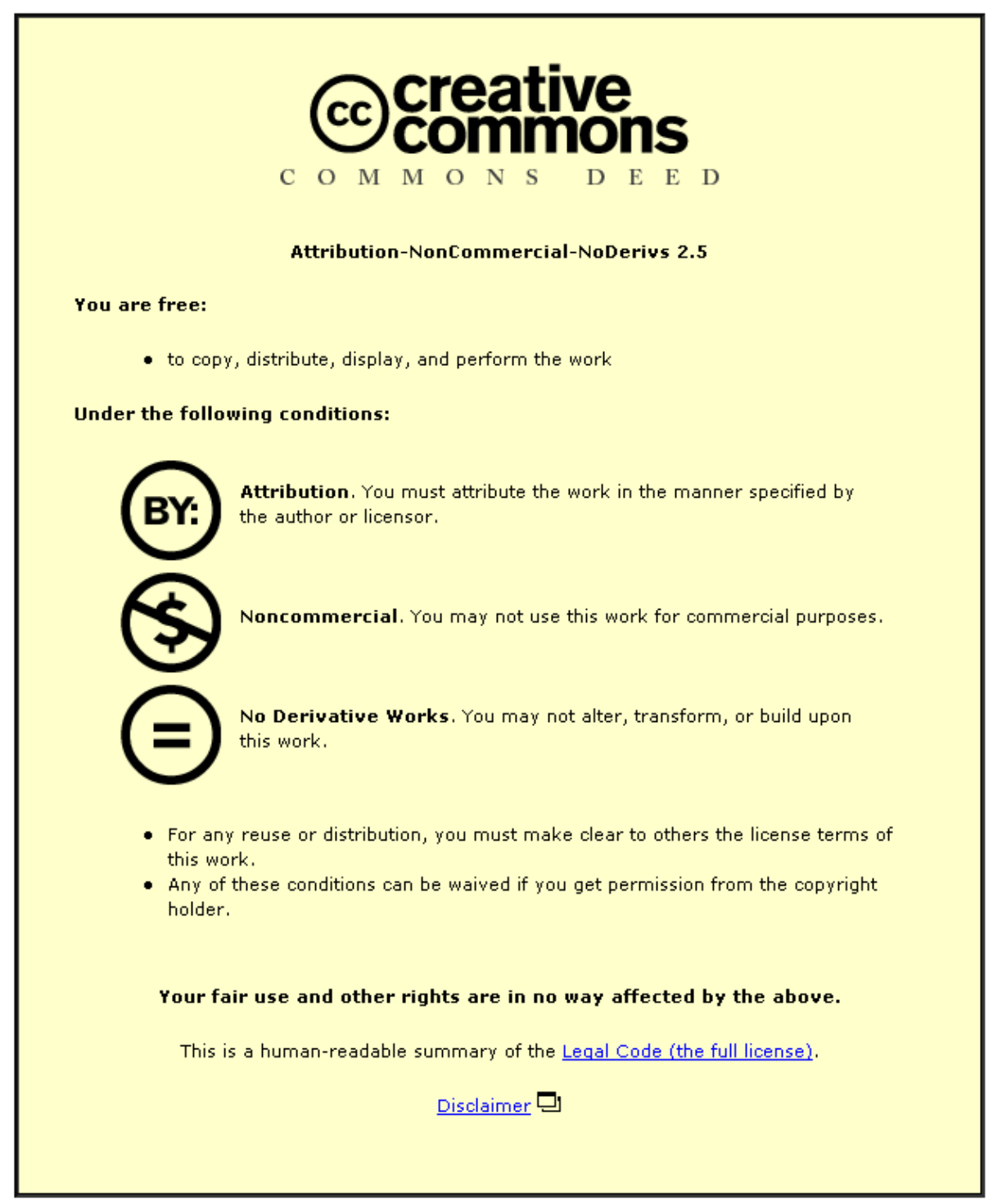

For the full text of this licence, please go to: http://creativecommons.org/licenses/by-nc-nd/2.5/ 


\title{
Simulation of photosensor-based hairiness measurement using digital image analysis
}

\author{
Yasar A. Ozkaya, Memis Acar and Mike R. Jackson \\ School of Mechanical and Manufacturing Engineering, Loughborough University \\ Loughborough, Leics, LE113TU, UK
}

\begin{abstract}
The hair-counting technique using photosensors is a common method to measure the hairiness of the yarns. However, the literature recognizes some deficiencies of the technique regarding the sensor limitations. This paper describes a computer vision approach to simulate the photosensors and to investigate the parameters effecting the hairiness measurement when using these sensors. An algorithm developed to simulate the photosensor signals is explained. The effects of sensor resolution, signal threshold level and selection of zero reference positions from the core are investigated. The correlation between the measurements taken from two different sides of the yarn core is also examined. Twenty yarn samples are tested using a Zweigle G565 hairiness tester, and the results are compared with the hairiness measurements from the simulated photosensor system using digital images.
\end{abstract}

Key words: Yarn hairiness, digital image analysis, sensor resolution.

\section{INTRODUCTION}

A common method used to measure the hairiness is based on photoelectric sensors placed at certain distances from the yarn core edge and counting number of signals generated by the hair shadows projected onto the sensors through some magnification elements (Lappage and Onions, 1964) or more generally through a slit (Ghosh et al., 1988; Ozkaya et al., 2005) as illustrated in Figure 1. In such systems, when the intensity of light drops below a certain percentage of the intensity of light when no interruption is present, then the sensor generates a signal indicating a hair intersection. In the system depicted in Figure 1, the resolution is determined by the width and the height of the slit, that is if there are two hairs separated by a distance less than the width of the slit parallel to the yarn axis or less than the height of the slit perpendicular to the yarn, it will not be possible to separate them by this system. Slack (1970) pointed out that on Shirley yarn hairiness meter (YHM), the fibres that are separated along the yarn length by less than $0.5 \mathrm{~mm}$ could not be resolved as separate fibres due to the size of the aperture. This restriction is important particularly for rotor spun yarns having surface fibres wrapped around the core (Barella et al. 1992).

Another important restriction when using photosensors arises from the variations of the yarn core diameter, and therefore, the zero length position of the hairs. If the sensor distance were set too close to the yarn core, then variations of the core diameter would cause a fixed sensor distance to result in misleading hair count. This, of course, affects all hair length distances. However, since the number of hairs increases exponentially approaching to the core, the problem is more amplified at short hair distances. The threshold level relative to the unblocked light intensity falling on to the sensor is also important when determining the number of hairs; if this is high then the measurements might be affected from noise and if it is low some fine fibres might not be detected by the sensor. On Shirley YHM, this level was selected so that a fibre with a diameter of as small as $12 \mu \mathrm{m}$ could safely be detected by the photocell (Ozkaya et al., 2005).

An image-processing technique that simulates the hair count measurement from conventional photosensors is presented in this paper. The technique also allows investigation of the effects of many parameters such as sensor resolution, core-edge detection and threshold levels on the measurements, highlighting possible drawbacks of the photosensor technology.

\section{DESCRIPTION OF THE TECHNIQUE}

A CCD line-scan system was developed at to capture digital image of the yarns. A Dalsa Spark 2048-pixel line scan 


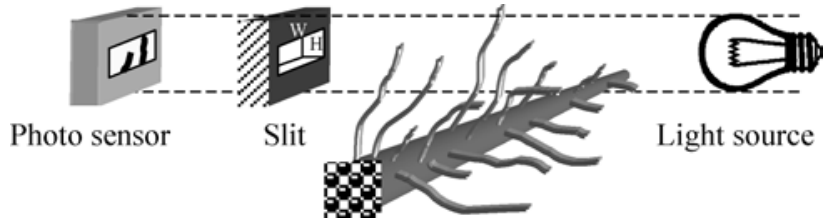

Figure 1 Principle of hair-counting method using a photosensor.

camera with a 100-mm macro lens giving $1 \times$ magnification is used for image acquisition. The maximum line rate of the camera is $18.8 \mathrm{kHz}$. The images are transferred to a PC through a Viper digital frame grabber. The pixel size of the camera is $14 \mu \mathrm{m} \times 14 \mu \mathrm{m}$ with a fill factor of $100 \%$. The yarns are backlit using a 50-W tungsten filament bulb. The line acquisition is triggered using an optical encoder attached to the yarn transfer system.

The line scan camera allows a scanning resolution of $14 \mathrm{scans} / \mathrm{mm}$ at a yarn speed of $80 \mathrm{~m} / \mathrm{min}$. The scanning resolution can be increased by decreasing the yarn transfer speed. However, 14 scans/mm is found to be the lower limit for yarn scanning since the hairs are lost below this resolution giving lower hairiness values. Images are processed using Wit 7.1 image-processing software and C programming language.

Based on the back-lit yarn imaging set-up and imageprocessing algorithms for hair-core-background separation in yarn images is described by Ozkaya et al. (2005). On a thresholded yarn image, a certain number of sub-windows are defined at certain distances from the yarn core as shown in Figure 2 to simulate the hair-counting technique using photosensors. The corresponding dimensions of the subwindows in the object plane are regarded as the dimensions

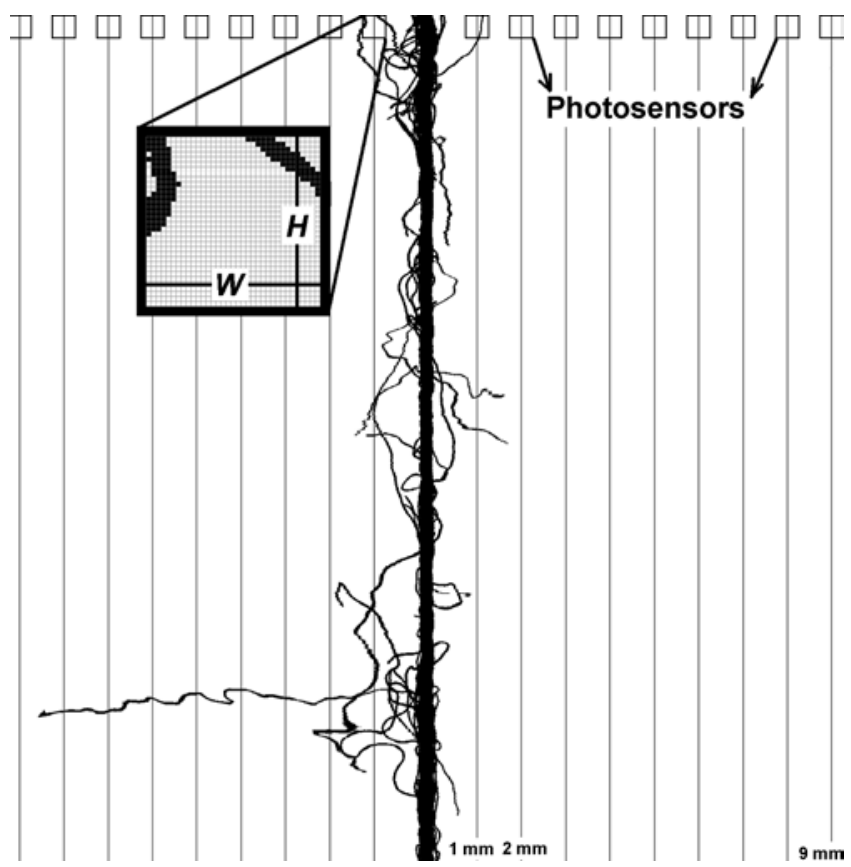

Figure 2 The sub-windows for simulating the photosensors.
Table 1 Specifications of the yarn samples used in the experiments

\begin{tabular}{|c|c|c|c|c|}
\hline \# & $\begin{array}{c}\text { Spin } \\
\text { method }\end{array}$ & Blend & $\begin{array}{r}\text { Yarn } \\
\text { count }\end{array}$ & $\begin{array}{c}\text { Twist } \\
\text { (turns/inch) }\end{array}$ \\
\hline 1 & Ring & 65/35 Cotton/polyester & Ne $10 / 1$ & 12.33 \\
\hline 2 & Ring & 65/35 Polyester/cotton & Ne $20 / 1$ & 17.49 \\
\hline 3 & Ring & $100 \%$ Polyester & Ne 10/1 & 11.38 \\
\hline 4 & Ring & 65/35 Cotton/polyester & Ne $10 / 1$ & 11.38 \\
\hline 5 & Ring & $100 \%$ Polyester & Ne $20 / 1$ & 17.49 \\
\hline 6 & Ring & 65/35 Cotton/polyester & Ne 20/1 & 16.1 \\
\hline 7 & Ring & 65/35 Cotton/polyester & Ne $20 / 1$ & 14.7 \\
\hline 8 & Ring & $100 \%$ Cotton & $\mathrm{Ne} 20 / 1$ & 16.1 \\
\hline 9 & Ring & $100 \%$ Cotton & Ne $10 / 1$ & 11.38 \\
\hline 10 & Ring & 65/35 Polyester/cotton & Ne $10 / 1$ & 12.3 \\
\hline 11 & Ring & 65/35 Polyester/cotton & $\mathrm{Ne} 30 / 1$ & 18.2 \\
\hline 12 & Ring & 60/40 Acrylic/wool & $\mathrm{Nm} 30 / 1$ & 12.19 \\
\hline 13 & Ring & 60/40 Acrylic/wool & $\mathrm{Nm} 30 / 1$ & 9.65 \\
\hline 14 & Ring & 70/30 Acrylic/wool & $\mathrm{Nm} 32 / 1$ & 13.08 \\
\hline 15 & Ring & $100 \%$ Cotton & Ne 60/1 & 29.21 \\
\hline 16 & Ring & $100 \%$ Cotton & Ne $10 / 1$ & 11.05 \\
\hline 17 & Ring & $100 \%$ Cotton & Ne $20 / 1$ & 15.24 \\
\hline 18 & Ring & $100 \%$ Cotton & Ne 30/1 & 19.56 \\
\hline 19 & Ring & $100 \%$ Cotton & $\mathrm{Ne} 30 / 1$ & 22.36 \\
\hline 20 & Ring & $100 \%$ Cotton & Ne 30/1 & 21.96 \\
\hline
\end{tabular}

of the slit depicted in Figure 1, and the sum of the pixel intensities within the sub-window is considered to be proportional to the intensity of light falling on the simulated photosensor. Initially, the effect of sensor resolution was investigated for simulated sensor resolutions of $100 \mu \mathrm{m}$ $\times 100 \mu \mathrm{m}, 500 \mu \mathrm{m} \times 100 \mu \mathrm{m}, 500 \mu \mathrm{m} \times 500 \mu \mathrm{m}$ and $1000 \mu \mathrm{m} \times 500 \mu \mathrm{m}$. By sliding the sub-windows vertically through the image row by row and calculating the total intensity within these windows for each row, a lightdistance profile is obtained for each sub-window. Figure 3 shows typical profiles for sub-windows at 1,2 and $3 \mathrm{~mm}$ from the core. These profiles are considered to be similar to the analogue electrical signals that would be obtained from photosensors placed at 1, 2 and $3 \mathrm{~mm}$ from the yarn core. After applying a threshold to these profiles, each $0-1$ transition is counted as a hair.

Twenty yarn samples listed in Table 1 are tested using a Zweigle G565 instrument. Three specimens of $50 \mathrm{~m}$ of each yarn were tested at the standard $50 \mathrm{~m} / \mathrm{min}$ yarn speed. Twelve of the yarn samples (sample numbers 1, 9, 10 and 12-20) were also tested using Uster 4 tester using $100-\mathrm{m}$ specimen of each yarn at the standard $400 \mathrm{~m} / \mathrm{min}$ yarn speed. Then, all 20 samples were imaged using the yarn-scanning system developed for this purpose. For each sample, 1250 images, each scanned at $14 \mathrm{scan} / \mathrm{mm}$ rate corresponding to a 25-m of yarn length, are captured and stored. This allowed testing different image-processing algorithms for the same yarn sections. Due to the time required for the computer to store images in real time, the yarn transfer speed was kept slow at $5 \mathrm{~m} / \mathrm{min}$ during image 

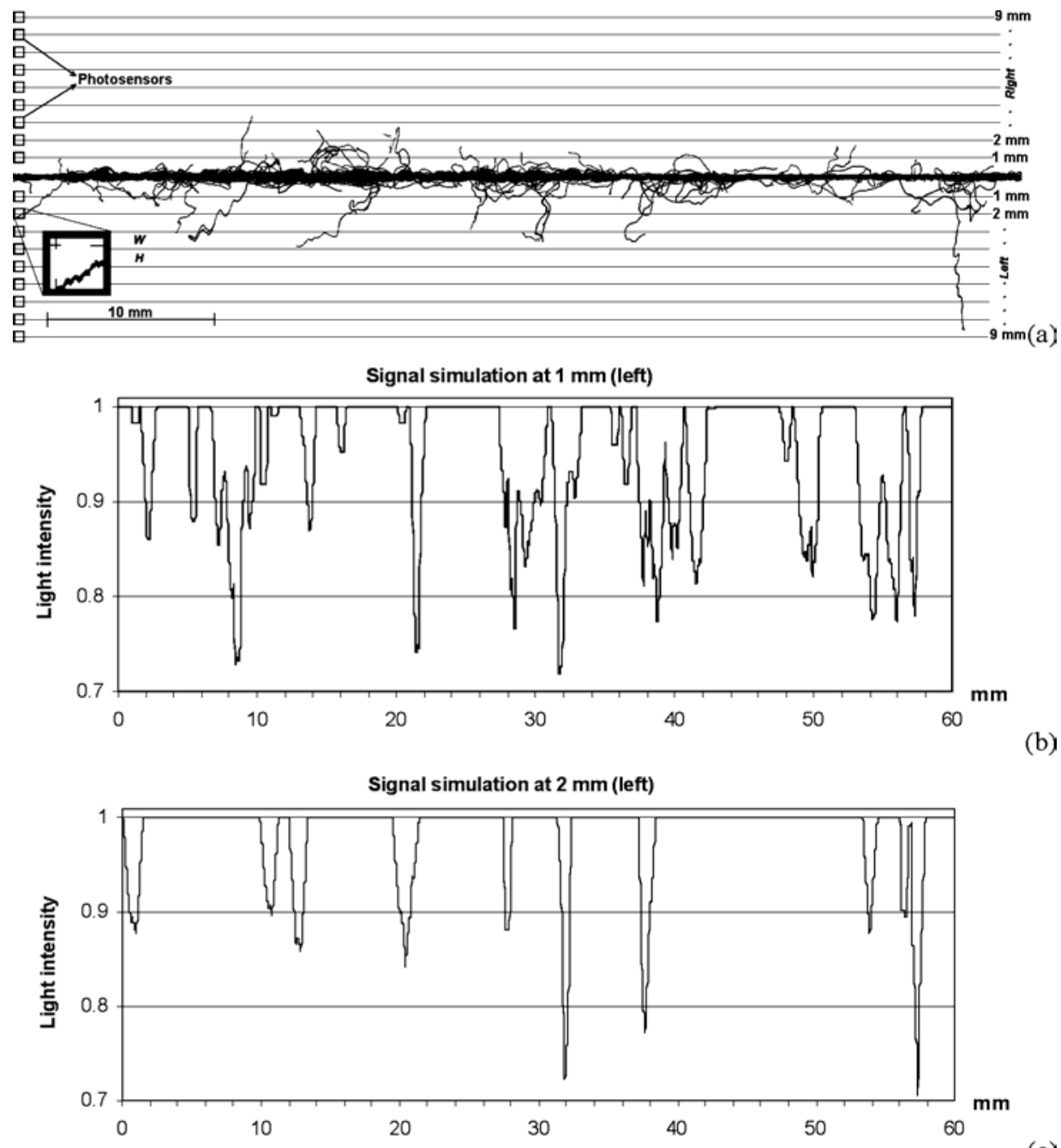

(b)

(c)

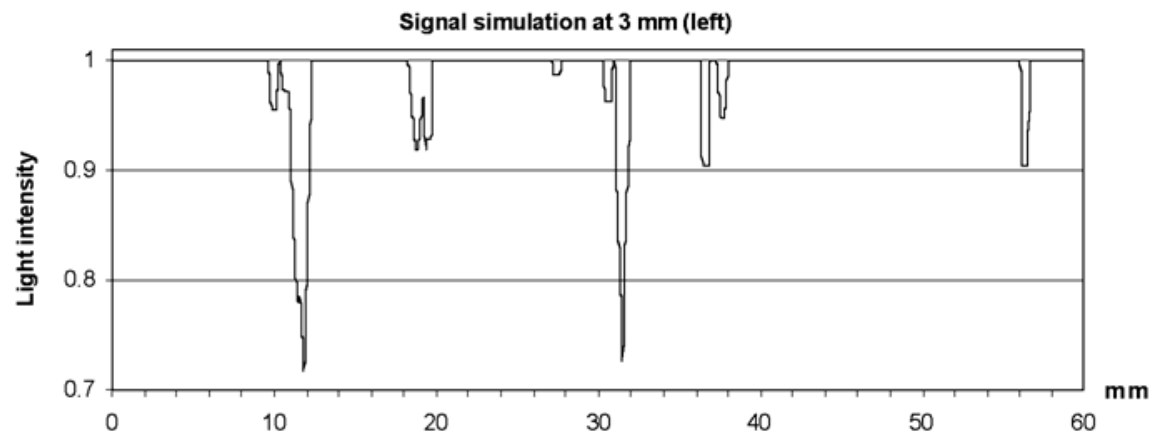

(d)

Figure 3 (a) Image of a yarn corresponding to $60 \mathrm{~mm}$ ((b)-(d)) simulated signals for photosensors 1,2 and $3 \mathrm{~mm}$ apart from the core.

acquisition, although the speed of the yarn can be as high $80 \mathrm{~m} / \mathrm{min}$ at 14 lines $/ \mathrm{mm}$ scan rate.

A 25-m specimen-length is found to be more than adequate following experiments with different lengths. Figure 4 shows the average $\mathrm{N} 1$ (the number of hairs at $1 \mathrm{~mm}$ from the core edge) measurements of eight yarn samples for different test lengths, where a steady N1 value can be observed after $10 \mathrm{~m}$ specimen-length. This test length is also found appropriate for determining the average number of hairs at other distances from the core (N2, . ., N9 are the number of hairs at 2, . , $9 \mathrm{~mm}$ from the core edge, respectively). However, a 50-m test length was used in determining the hairiness values (N1-N9) to imitate the test lengths used by Zweigle.

When performing the photosensor simulation, the processing algorithm finds a reference core edge position 


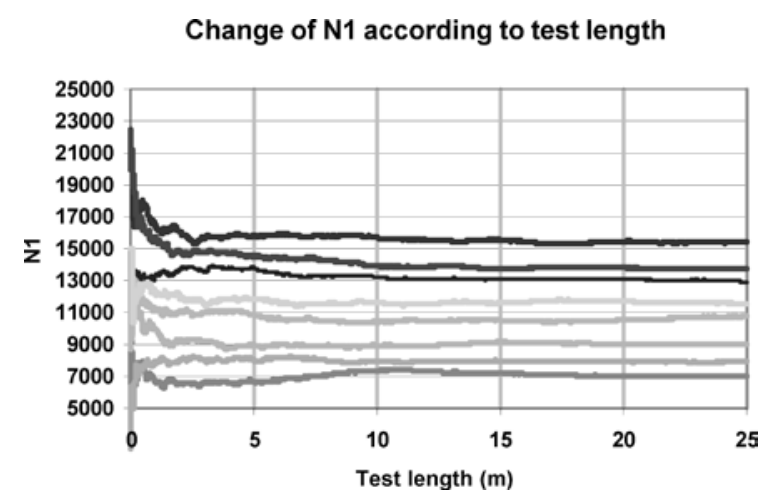

Figure 4 Change of average N1 values for eight yarn samples according to the test length.

Table 2 Comparison of measurements from image-processing technique and Zweigle G565 hairiness tester

\begin{tabular}{|c|c|c|c|c|c|c|}
\hline \multirow{2}{*}{$\begin{array}{l}\text { Yarn } \\
\#\end{array}$} & \multicolumn{2}{|r|}{ N1 } & \multicolumn{2}{|r|}{ N2 } & \multicolumn{2}{|r|}{ S3 } \\
\hline & G565 & Simulation & G565 & Simulation & G565 & Simulation \\
\hline 1 & 12028 & 11155 & 2469 & 2293 & 767 & 858 \\
\hline 2 & 9120 & 9199 & 1616 & 1608 & 406 & 629 \\
\hline 3 & 15824 & 15763 & 3506 & 3074 & 826 & 981 \\
\hline 4 & 13552 & 13233 & 3290 & 2668 & 1176 & 955 \\
\hline 5 & 9294 & 9301 & 1663 & 1413 & 377 & 393 \\
\hline 6 & 10410 & 11072 & 2556 & 2028 & 830 & 715 \\
\hline 7 & 11092 & 9489 & 2747 & 1688 & 907 & 534 \\
\hline 8 & 13772 & 11853 & 3696 & 2491 & 1372 & 892 \\
\hline 9 & 15278 & 17564 & 4044 & 3827 & 1566 & 1532 \\
\hline 10 & 12124 & 12348 & 2810 & 2408 & 862 & 956 \\
\hline 11 & 8810 & 7400 & 1928 & 1215 & 595 & 419 \\
\hline 12 & 6996 & 5308 & 2405 & 1868 & 1597 & 2529 \\
\hline 13 & 9196 & 7218 & 3648 & 2628 & 2472 & 2653 \\
\hline 14 & 11616 & 11427 & 4387 & 3521 & 2914 & 2863 \\
\hline 15 & 7908 & 5200 & 1783 & 1026 & 720 & 533 \\
\hline 16 & 14470 & 14920 & 4729 & 4720 & 2094 & 3710 \\
\hline 17 & 12834 & 11712 & 4649 & 3840 & 2241 & 2860 \\
\hline 18 & 9070 & 9643 & 2301 & 2565 & 796 & 1343 \\
\hline 19 & 11390 & 11618 & 3423 & 3117 & 1302 & 1058 \\
\hline \multirow[t]{2}{*}{20} & 11578 & 12622 & 3475 & 3287 & 1267 & 1669 \\
\hline & \multicolumn{2}{|c|}{$R=0.939726$} & \multicolumn{2}{|c|}{$R=0.919491$} & \multicolumn{2}{|c|}{$R=0.882095$} \\
\hline
\end{tabular}
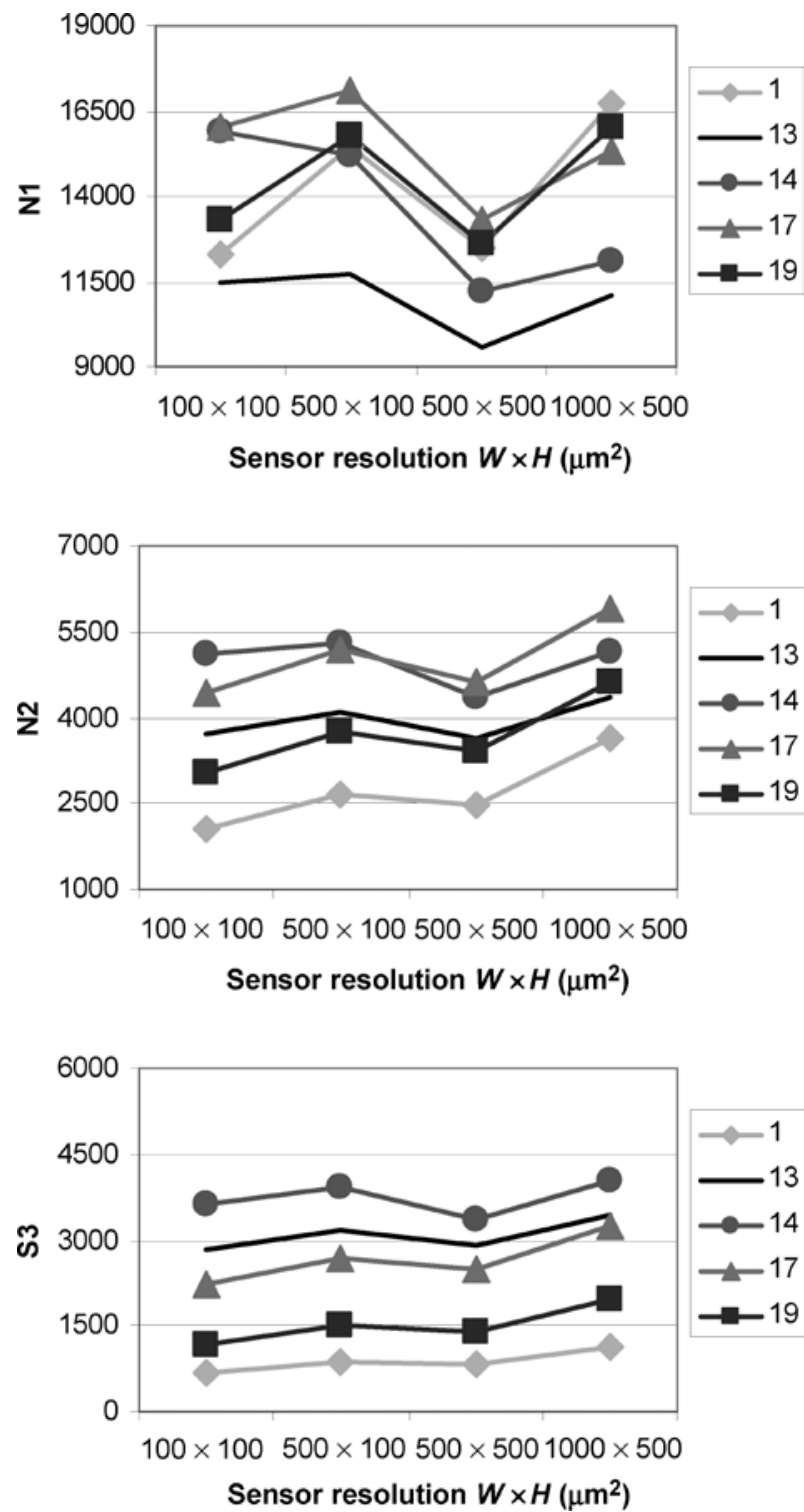

Figure 5 Comparison of N1, N2 and S3 measurements using different sensor dimensions.

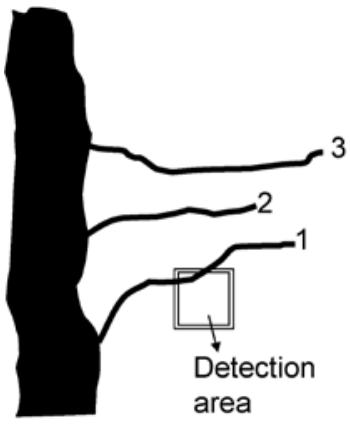

(a)

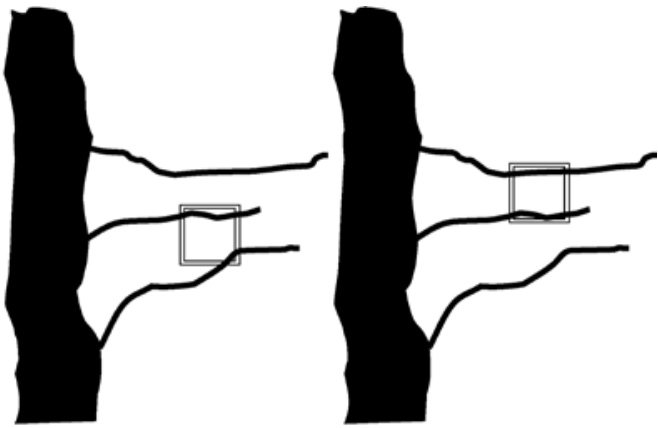

(b)

(c)

Figure 6 A hair acting as a bridge. (a) Hair 1 detected by the sensor; (b) the sensor signal is not changed as hair 2 is visible to the sensor; (c) signal still not changed as hair 3 is visible. 

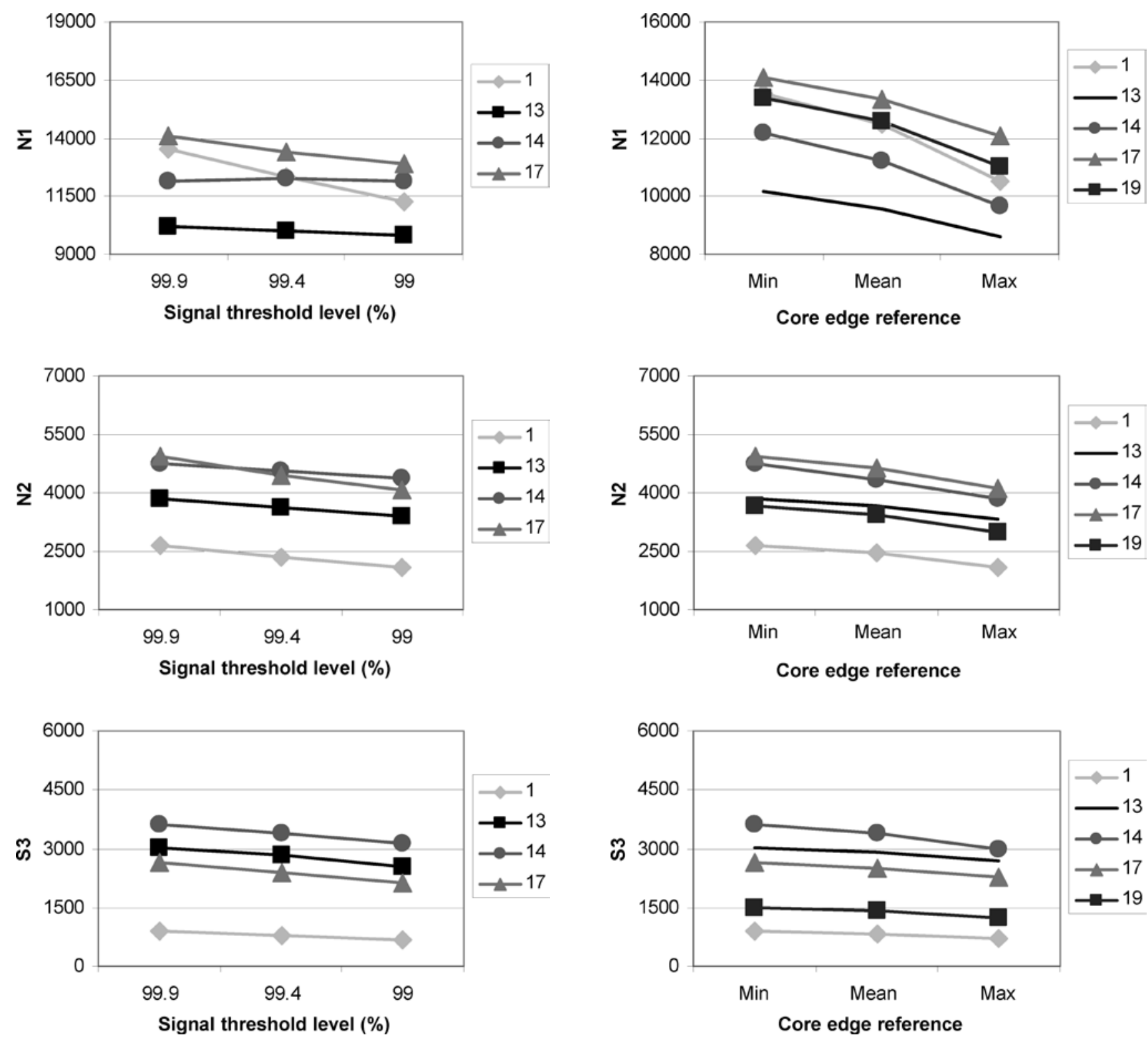

Figure 7 Comparison of N1, N2 and S3 measurements using different signal threshold levels.

automatically for every image that corresponds to $20 \mathrm{~mm}$ of yarn length (1400 rows). In Zweigle G565 hairiness meter, the core edge is located once at the beginning of the test by moving the yarn transport rollers at the measuring zone manually until the core does not block past the reference point. The exact method how the core edge is determined and the precision of this alignment could not be found in the literature. Three different configurations are tested to investigate the effect of zero reference line to overall measurements. The first one takes the closest edge of the core to the core axis among 1400 rows (Min), whereas the second one takes the farthest edge position from the core axis (Max) and the final one calculates the zero reference line by taking the average of the core positions of 1400 rows (Mean).

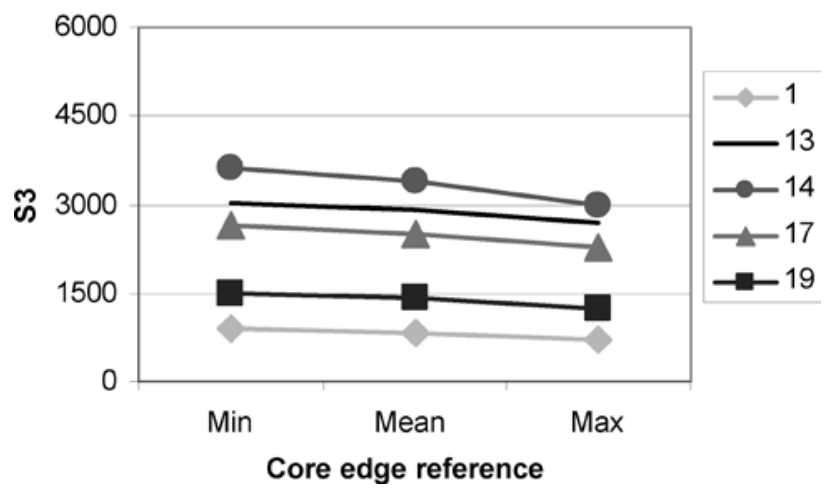

Figure 8 Comparison of N1, N2 and S3 measurements using different zero length positions.

\section{RESULTS AND DISCUSSION}

Figure 5 compares measurements using four different resolution settings from five yarn samples chosen for their visually different hairiness characteristics. It can be seen that using different sensor resolutions does not affect the hairiness measurements of all yarns tested in the same way. For instance, the N1 value for sample 1 is largest when using a $1 \mathrm{~mm} \times 0.5 \mathrm{~mm}$ sensor compared to the values obtained with other sensor resolutions for the same sample. Sample 14, on the other hand, has much less value at this resolution than it has at $0.1 \mathrm{~mm} \times 0.1 \mathrm{~mm}$ resolution. Another interesting point to note is that the N1 value is smaller for sample 14 than sample 1 at $0.5 \mathrm{~mm} \times 0.5 \mathrm{~mm}$ resolution, whereas it is larger at a higher resolution of 0.1 $\mathrm{mm} \times 0.1 \mathrm{~mm}$. Visually, sample 14 has denser hairs around 


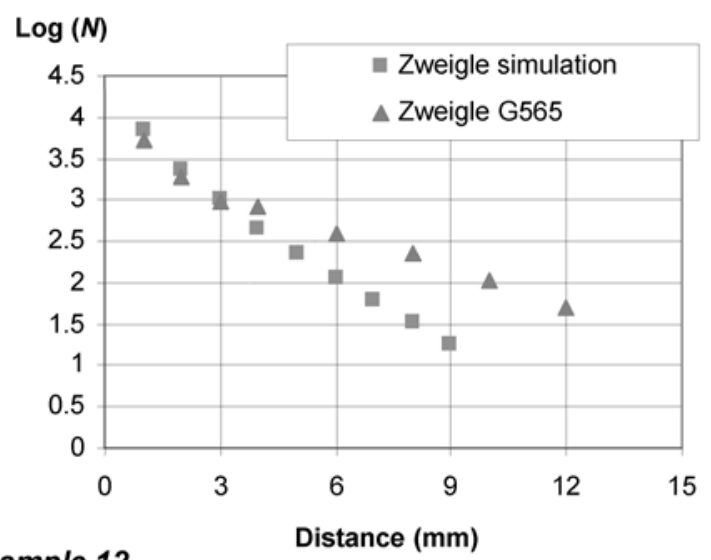

Sample 12

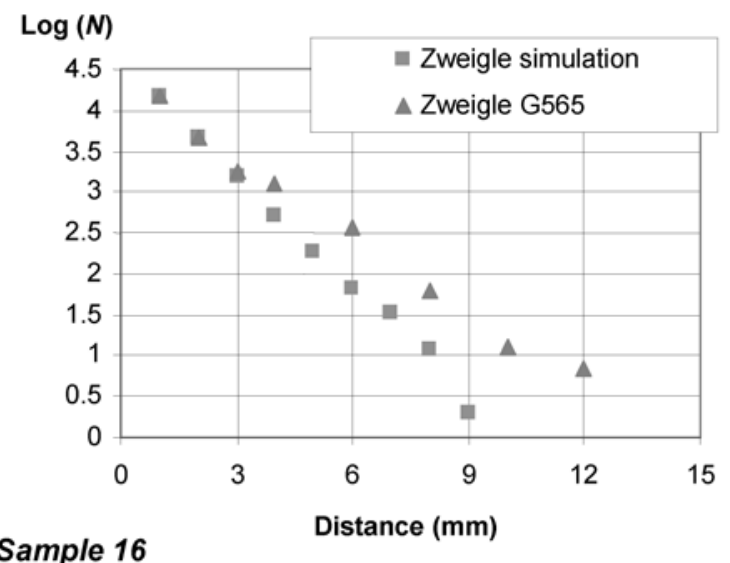

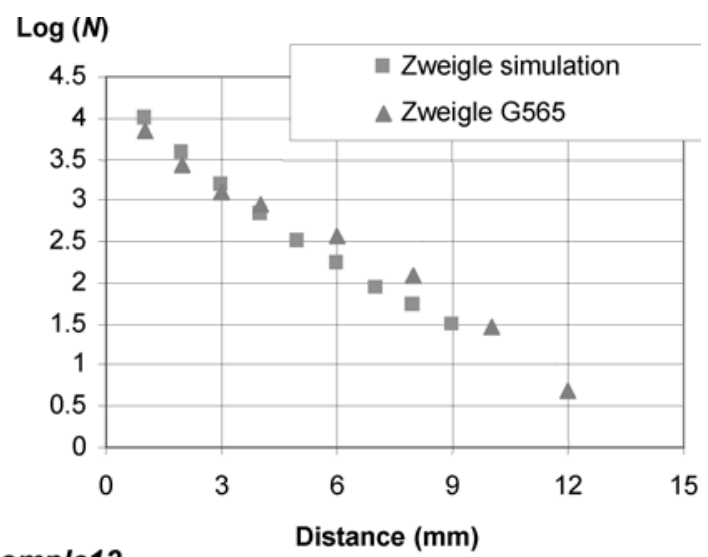

Sample13

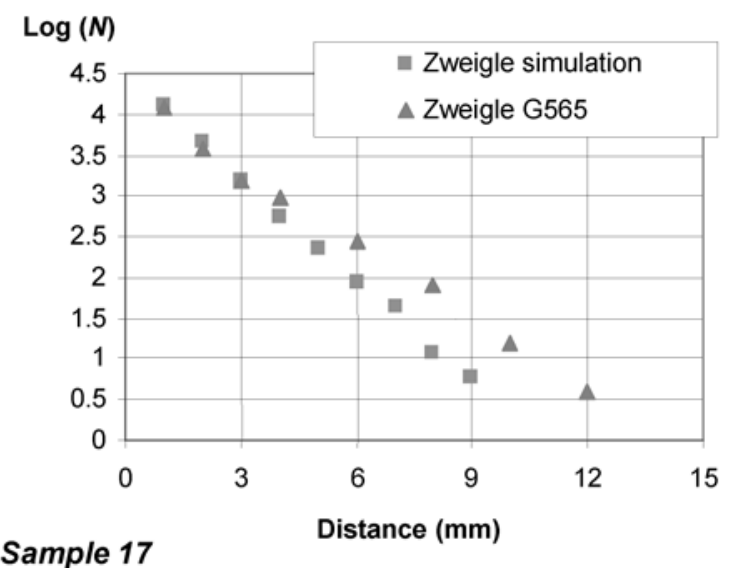

Figure 9 Comparison of hair numbers from Zweigle G565 and the yarn-scanning system simulation for four samples with long hairiness.

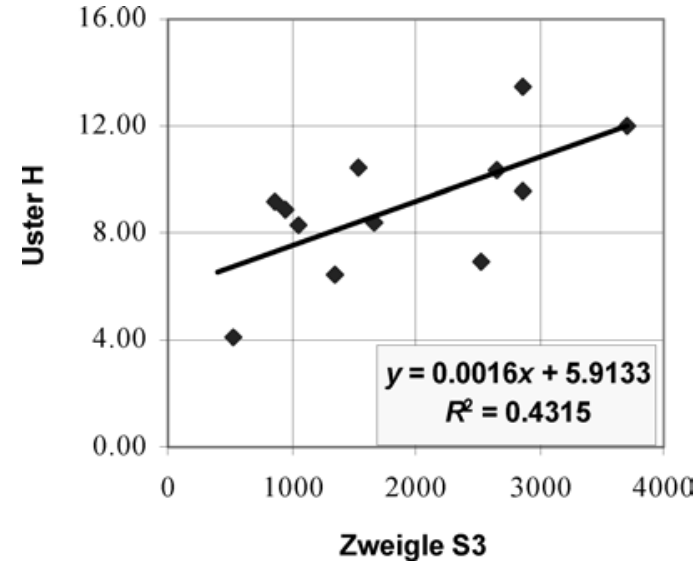

Figure 10 Comparison of USTER H with Zweigle S3.

the core and the results show that higher sensor resolutions are required to differentiate the densely packed short hairs. Figure 6 illustrates how three hairs can be counted as a single hair due to the large size of the sensor. It can be argued that N1 measurements with low-sensor resolutions do not give comparable results for different yarns especially those having densely distributed hairs. Since the hairs are spa- tially more distinctly separated at distances greater than 1 $\mathrm{mm}$ from the core, the effect of sensor resolution decreases at these distances and the hair count is more consistent with different sensor resolutions between different samples.

The effect of threshold levels have been investigated with four different yarns at N1, N2 and S3 levels, where S3 is the sum of the number of hairs at distances equal and greater than $3 \mathrm{~mm}$. Figure 7 shows the effect of using different threshold levels. The number of intersections generally decreases as the threshold level is decreased. However for sample 14, decreasing the threshold level down to a certain level increases the number of hairs at $1 \mathrm{~mm}$ from the core due to the disappearance of some points in the profile acting as a bridge. When digitizing the simulated photosensor signal, a threshold level at $99.9 \%$ allows any hair pixel entering the photosensor zone to change the signal from 1 to 0 . This level can confidently be used in image processing, since a threshold operation is carried out in the pre-processing stage. However, when using an actual photosensor, such a threshold level will not practically be possible due to noise and need for a higher tolerance for light intensity fluctuations.

Figure 8 shows the results of the three different zero reference lines on the hair count measurements. It can 

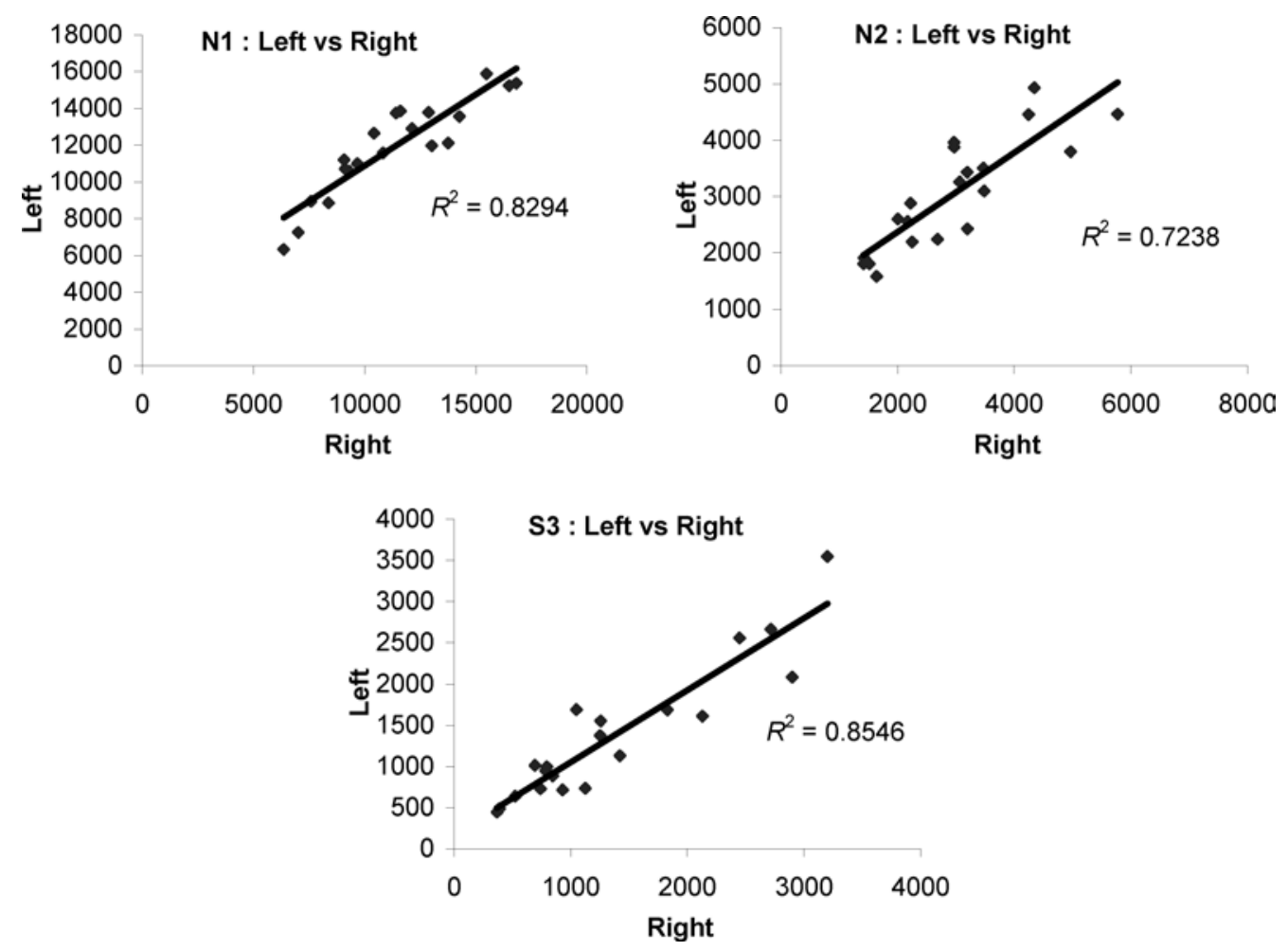

Figure 11 Comparison of N1, N2 and S3 measurements from left and right sides of the yarn.

be seen that as the reference position gets closer to the core axis, the number of intersections increases, which is expected considering the fact that the number of hairs decreases exponentially going further from the core. It is interesting to note that the effect of reference point is very significant for $\mathrm{N} 1$ hair counts that the hair counts decrease by around $20 \%$ as the reference line is moved from Max to Min. This shift of the reference line corresponds to around $100 \mu \mathrm{m}$ on average for most of the samples. It has been shown that the selection of the zero reference line strongly affects hair count measurements with two increasing amplitude closer to the core, thus requires a very high precision.

Table 2 shows the comparison of the N1, N2 and S3 measurements using these parameters and the Zweigle G565 hairiness tester. To simulate Zweigle G565 hairiness tester using the developed method, the sensor dimensions are set to $0.5 \mathrm{~mm} \times 0.5 \mathrm{~mm}$, the signal threshold is set to $99.9 \%$ of the maximum intensity and the reference line is selected as the mean distance from the core axis for every image in the simulations. For the developed system, the number of intersections is calculated from the average of intersections found on the right and left sides of the core. It can be seen that the $\mathrm{N} 1$ and N2 values from Zweigle and the developed system are often in very good agreement. However, for some samples, the latter gave higher hair counts. This may be due to the difference in setting the zero reference point in two testers, which is optically determined and set with high precision on the yarn-scanning system and probably not as precisely on Zweigle, due to its manual, mechanical adjustment procedure. For S3 measurements, on the other hand, the Zweigle exhibits higher values for a number of samples. This can be due to the fact that the S3 values tend to increase according to the test speed as reported by Wang (1997); the speed used on the yarn-scanning system is $5 \mathrm{~m} / \mathrm{min}$ whereas this is 50 $\mathrm{m} / \mathrm{min}$ on Zweigle, a possible cause of higher S3 values recorded by the Zweigle. According to Wang and Chang (1999), the differing contact conditions between the yarns and the various yarn guides on different hairiness testers may also affect the hairiness measurements. Nevertheless, the overall correlations between two testers were quite significant with correlation coefficients of $0.94,0.92$ and 0.88 for N1, N2 and S3 measurements, respectively.

Barella and Manich (1993) showed that the hair counts measured on Zweigle G565 exhibit two different trends on a logarithmic scale one between 1 and $3 \mathrm{~mm}$ and the other above $3 \mathrm{~mm}$. For yarn samples with long-hairiness tested during this research, this behaviour has also been observed on measurements from this instrument. However, for the same samples, the measurements from yarn-scanning system did not exhibit such a discrepancy. This is quite evident from Figure 9, where the numbers of hairs are plotted against the distance from the core on a logarithmic scale for four different samples with long hairiness.

In Figure 10, the S3 values from Zweigle G565 are compared with Uster's $H$ index for samples 1, 9, 10 and 12-20. A clear correlation could not be observed between these two common hairiness indices, confirming similar findings reported in the literature. 
It is commonly accepted that two sides of a yarn statistically exhibit the same behaviour in terms of hairiness. Figure 11 shows the correlations for N1, N2 and S3 measurements between the left and right sides of the core. The graphs show that the measurements from left and right sides reasonably agree with each other, but the correlations are not as high as one would expect. However, it must be noted that these values represent $25 \mathrm{~m}$ of yarn lengths and statistically, the correlation coefficients might increase for longer test lengths.

\section{CONCLUSIONS}

An image analysis technique is demonstrated to simulate photoelectric sensors used for counting the number of hairs at fixed distances from the core. The effect of parameters, such as the dimensions of the sensor, signal threshold level and the zero reference point on the measurements, is shown. It is found that a sensor resolution of $0.5 \mathrm{~mm}$ $\times 0.5 \mathrm{~mm}$, which represents a typical photoelectric sensor resolution, would not be adequate to distinguish between N1 hair count values of different yarns. The need for a very high precision in determining the zero reference point is also addressed. It is observed that with appropriate sensor parameters, the computer vision technique can be very successful in simulating the N1, N2 and S3 measurements from Zweigle G565 hairiness tester. However, a discrepancy is observed between two methods for hair counts above $3 \mathrm{~mm}$, where Zweigle exhibited higher values. This is thought to be due to the difference in test speed and other possible physical differences in the transport systems of the two testers.

\section{ACKNOWLEDGMENTS}

This project has been sponsored by Loughborough University's School of Mechanical and Manufacturing Engineering. We also would like to thank both the Textile Engineering Department of Istanbul Technical University for providing the yarn samples and North Carolina State University's College of Textiles for enabling the use of yarn-testing facilities.

\section{REFERENCES}

Barella, A., \& Manich, A. M. (1993). The hair length distribution of yarns, measured by means of the Zweigle G565 hairiness meter. J. Text. Inst., 84 (3), 326-335.

Barella, A., Coll-Totosa, L., Espiell, G. S., \& Bardi, X. (1992). Neue Gesichtspunkte bei der Messung und Bewertung der Haarigkeit [New criteria for the measurement and evaluation of hairiness]. Textil Praxis, 47 (12), 1116-1125.

Ghosh, S. N., Das, D. K., Bhattacharya, G. K., Jain, A. K., Sil, N. K., \& Mukhopadhyay, B. N. (1988). An electronic instrument for measuring the hairiness of jute yarn. J. Text. Inst., 79( 4), 634-640.

Lappage, J., \& Onions, W. J. (1964). An instrument for the study of yarn hairiness. J. Text. Inst., 55 (8), T381395.

Ozkaya Y. A., Acar M and Jackson M.R. (2005) Digital image processing and illumination techniques for yarn characterisation. The Journal of Electronic Imaging, 14(2), 2005, 13 pp

Slack, J. K. (1970). An instrument for measuring the hairiness of yarns. J. Text. Inst.,_61 (9), T428-437.

Wang, X. (1997). The effect of testing speed on the hairiness of ring-spun and Sirospun yarns. J. Text. Inst., 88 (1), Fibre Science and Textile Technology (2), 99-106.

Wang, X., \& Chang, L. (1999). An experimental study of the effect of test speed on yarn hairiness. Text. Res. J., 69 (1), 25-29. 